\title{
Establishing an Orthogeriatric Service
}

\author{
Terence Ong and Opinder Sahota
}

\subsection{Introduction}

Older people with fragility fractures do not present with the acute problem of the fracture only. Alongside their broken bone, many present concurrently with medical illnesses, frailty, multi-morbidity and disability. They are at risk of future falls and/or fractures, have a challenging peri-operative period, are at risk of medical complications and many do not return to their pre-fracture level of function. Orthogeriatric care is an adaption of the Comprehensive Geriatric Assessment (CGA) [1, 2], which is a multidimensional, interdisciplinary assessment and treatment of an older person. This co-management model of care with CGA principles, bringing together the relevant multidisciplinary expertise in fragility fracture management, has been shown to be the most effective way to address the complex healthcare needs of these patients and deliver improved outcomes [1, 3, 4]. Orthogeriatric care is now established as the ideal model of care for hip fracture management and is recommended in several national guidelines (see Fragility Fracture Network website-select a region and then choose Fragility Fracture Care Guidelines option) [5].

This chapter is a component of Part 2: Pillar I.

For an explanation of the grouping of chapters in this book, please see Chapter 1— "The Multidisciplinary Approach to Fragility Fractures Around the World—An Overview".

\footnotetext{
T. Ong (ه)

Faculty of Medicine, University of Malaya, Kuala Lumpur, Malaysia

e-mail: terenceong@ doctors.org.uk

O. Sahota

Department of Healthcare for Older People,

Nottingham University Hospitals NHS Trust, Nottingham, UK

e-mail: opinder.sahota@nuh.nhs.uk 
Different models of hip fracture orthogeriatric services have been described depending on how the different orthopaedic and geriatric medicine services interact with each other $[3,6]$. The most integrated model of co-management has demonstrated the best outcome in time to surgery, hospital length of stay and survival $[3,4,7]$. This chapter focuses on the framework required to establish such an orthogeriatric service. The steps detailed here are not prescriptive but should provide the guidance required to either start the service or develop parts of the existing service.

\subsection{Designing the Orthogeriatric Service}

\subsubsection{Step 1: Process Mapping the Hip Fracture Pathway}

An orthogeriatric service needs to consider the entire journey of the patient with a hip fracture, from their presentation to the Emergency Department all the way through to their rehabilitation and recovery. Hence, an important initial step to understand the local hip fracture pathway and how the future orthogeriatric service can be delivered locally is by performing a mapping exercise. The mapping exercise has to be a detailed assessment of each phase of care during the patients' hospital journey from what happens in the Emergency Department, pre-operatively, during the operation, after the operation and rehabilitation period. In each phase, the mapping exercise needs to specify what the treatment goals are (principles of care) and how these goals can be delivered (explicit care delivered) (Table 5.1).

Another benefit of mapping the hip fracture pathway is that it facilitates information gathering to justify an orthogeriatric service locally. Orthogeriatric care is still not a routine practice in many parts of the world. Moving hip fracture care from the traditional model of an orthopaedic team overseeing care with reactive medical input, to a co-management model will require justification that such a service is required. This is especially important in places where musculoskeletal health is not part of a national agenda and receives little attention. Extracting information and translating clinical evidence generated from other units or countries may not suffice. Healthcare managers would also be more receptive to establishing a service with local data. Hence, this mapping exercise should also attempt to generate data to serve two important purposes:

Table 5.1 An example of a mapping exercise of an orthogeriatric service across the different phases of care and components of care delivered that need to be delivered

\begin{tabular}{|c|c|c|}
\hline Phases of care & Principles of care & Care delivered \\
\hline $\begin{array}{l}\text { Emergency } \\
\text { Department } \\
\text { (ED) }\end{array}$ & $\begin{array}{l}\text { 1. Prompt fracture } \\
\text { identification } \\
\text { 2. Pain relief } \\
\text { 3. Transfer to trauma/ } \\
\text { orthopaedic wards }\end{array}$ & $\begin{array}{l}\text { 1. Early clinical and radiological } \\
\text { identification of a hip fracture } \\
\text { 2. Prompt assessment of pain and analgesia } \\
\text { appropriate to pain severity } \\
\text { 3. Minimise delay in transferring patient to } \\
\text { orthopaedic or trauma units }\end{array}$ \\
\hline
\end{tabular}


Table 5.1 (continued)

\begin{tabular}{|c|c|c|}
\hline Phases of care & Principles of care & Care delivered \\
\hline $\begin{array}{l}\text { Pre-operative } \\
\text { phase }\end{array}$ & $\begin{array}{l}\text { 1. Multidisciplinary team } \\
\text { involvement } \\
\text { 2. Pre-operative } \\
\text { assessment and } \\
\text { optimisation of } \\
\text { co-pathology/ } \\
\text { co-morbidities } \\
\text { 3. Risk stratification for } \\
\text { adverse outcomes }\end{array}$ & $\begin{array}{l}\text { 1. Early involvement of orthogeriatric care } \\
\text { team to agree surgical, anaesthesia and } \\
\text { medical plan } \\
\text { 2. Clear documentation and information } \\
\text { sharing between specialties, e.g., using a } \\
\text { joint admission clerking trauma booklet } \\
\text { 3. Adequate pain management before } \\
\text { surgery and appropriate use of nerve } \\
\text { blocks } \\
\text { 4. Optimisation of co-pathology and } \\
\text { co-morbidities (e.g., fluid status, delirium, } \\
\text { anaemia, glycaemic control, } \\
\text { anticoagulation) } \\
\text { 5. Implementation of standardised guidelines } \\
\text { in commonly encountered problems (e.g., } \\
\text { anticoagulation reversal, blood } \\
\text { transfusion, delirium management) } \\
\text { 6. Utilise validated hip fracture risk } \\
\text { stratification tool (e.g., Nottingham Hip } \\
\text { Fracture Score) and agree to appropriate } \\
\text { ceilings of care } \\
\text { 7. Agreed pathways to a specialist } \\
\text { investigation (e.g., magnetic resonance } \\
\text { imaging for occult fracture, } \\
\text { echocardiogram to assess cardiac } \\
\text { function) }\end{array}$ \\
\hline Operative phase & $\begin{array}{l}\text { 1. Timely surgery } \\
\text { 2. Choice of anaesthesia } \\
\text { and surgical technique } \\
\text { as appropriate for the } \\
\text { patient }\end{array}$ & $\begin{array}{l}\text { 1. Minimise wait for an operation } \\
\text { 2. Adequate staff and theatre capacity } \\
\text { 3. Agreed prophylactic antibiotic treatment } \\
\text { 4. Surgical and anaesthetic plan in place } \\
\text { delivered by adequately skilled clinicians } \\
\text { 5. Clear post-operative instructions, } \\
\text { including weight-bearing status } \\
\text { 6. Identification of those that require more } \\
\text { intense post-operative monitoring } \\
\text { 7. Target haemoglobin and criteria for } \\
\text { transfusion }\end{array}$ \\
\hline $\begin{array}{l}\text { Post-operative } \\
\text { phase }\end{array}$ & $\begin{array}{ll}\text { 1. } & \text { Mobilisation } \\
\text { 2. } & \text { Minimising hospital } \\
\text { complications } \\
\text { 3. Nutrition support } \\
\text { 4. Continence care } \\
\text { 5. Prevention of pressure } \\
\text { sores } \\
\text { 6. Planning for post- } \\
\text { hospital care }\end{array}$ & $\begin{array}{l}\text { 1. Routine review by orthogeriatric team } \\
\text { members to identify complications early } \\
\text { and facilitate recovery } \\
\text { 2. Early mobilisation and identification of } \\
\text { barriers (e.g., pain, delirium, } \\
\text { hypovolaemia, anaemia) } \\
\text { 3. Identification of those at risk of } \\
\text { malnutrition and nutrition supporting } \\
\text { strategies } \\
\text { 4. Bowel and continence care } \\
\text { 5. Regular review of pressure areas } \\
\text { 6. Identifying those that would require } \\
\text { extended venous thromboprophylaxis }\end{array}$ \\
\hline
\end{tabular}


Table 5.1 (continued)

\begin{tabular}{|c|c|c|}
\hline Phases of care & Principles of care & Care delivered \\
\hline Rehabilitation & $\begin{array}{l}\text { 1. Transfer of care out of } \\
\text { the hospital with the } \\
\text { right support in place } \\
\text { 2. Information sharing } \\
\text { with patient and } \\
\text { primary care providers } \\
\text { 3. Falls and fracture risk } \\
\text { assessment and } \\
\text { treatment }\end{array}$ & $\begin{array}{l}\text { 1. Routine and regular multidisciplinary } \\
\text { team meetings to discuss recovery and } \\
\text { plan for post-hospital care } \\
\text { 2. Minimise delay and wait for community } \\
\text { rehabilitation } \\
\text { 3. Identification of risk factors for falls and } \\
\text { fractures Implementing individualised } \\
\text { falls and fracture prevention plan }\end{array}$ \\
\hline
\end{tabular}

- Convincing people that there is a problem-gather data on local hip fracture epidemiology with an idea of absolute numbers presenting to the local hospital, and if available, how this has changed over time.

- Convincing people that orthogeriatric co-management is the solution-demonstrate the characteristics and outcomes of this patients that would require orthogeriatric co-management, that is, fragility fracture and frailty needs.

\subsubsection{Step 2: Identify a Core Multidisciplinary Team and Form a Steering Group}

Many healthcare professionals with different discipline backgrounds have important contributions to make to high-quality care for older patients with hip fractures. Mapping the pathway allows identification of these key members of the interprofessional multidisciplinary team (MDT). These key members usually include:

- Orthopaedic surgeon

- Physician with expertise in older people, frailty, trauma and bone health (e.g., ortho-geriatrician)

- Anaesthetist

- Nurse

- Physiotherapist

- Occupational therapist

This is not an exhaustive list as many successful services are supported by other health professionals such as social workers, clinical pharmacists, dieticians, fracture liaison services and radiology. The key to efficient multidisciplinary working has to be coordination and communication between the various team members. Responsibility is shared across the pathway depending on the patient's clinical need. For instance, the operative procedure is the responsibility of the surgeon and managing medical barriers to early mobilisation is better led by the geriatrician. 
Table 5.2 Geriatric medicine competencies in the management of hip fractures. Adapted from training requirements for UK specialist trainees in Geriatric Medicine in Orthogeriatrics [9]

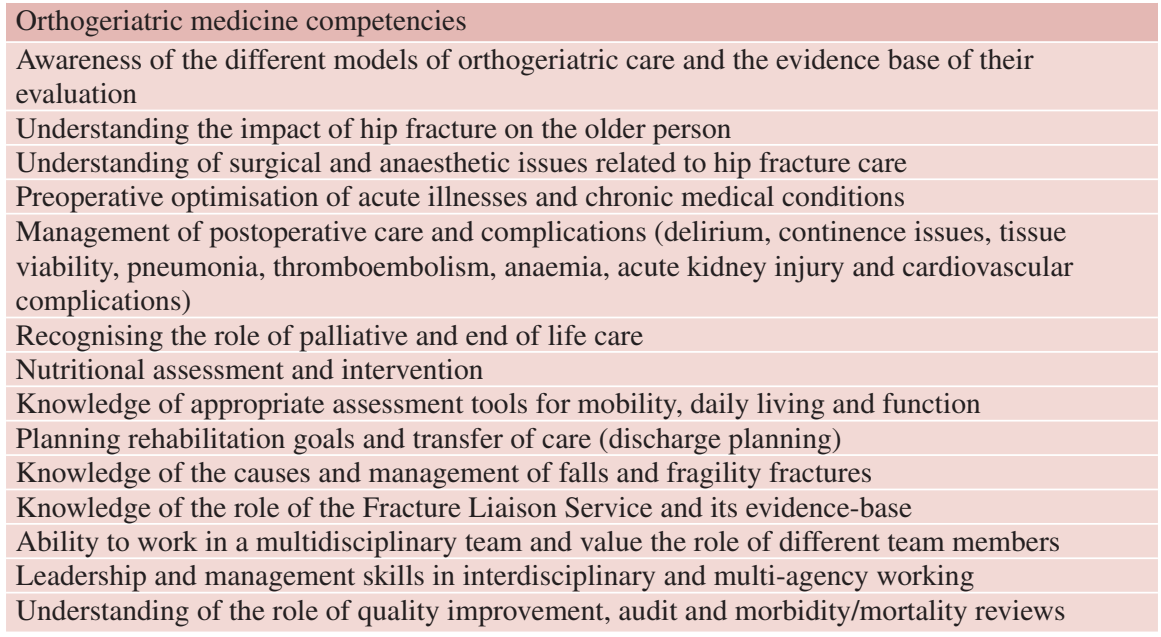

Appropriate organisation of ward rounds and the use of a common admission/ assessment proforma can support much of this MDT working. Many admission/ assessment proformas are available for download from sites such as the UK National Hip Fracture Database (NHFD) in its resources section [8].

However, in many countries the input from geriatricians, i.e., physicians with expertise in managing frail older people, is limited because either the number of practising geriatricians is small, or that geriatric medicine is still not recognised as its own medical specialty. In such a situation, geriatric medicine competencies can be acquired by other physicians, such as hospital internists or general physicians, to support the care of older patients with hip fractures. An example of geriatric medicine competencies in orthogeriatric care is listed in the table below (Table 5.2).

\subsubsection{Step 3: Analyse and Review the Patient Pathway}

The key MDT members identified in the earlier step will also form the steering group that will review the whole hip fracture pathway, determine the overall strategy (short, medium and long term aims), review quality improvement work and discusses clinical governance issues through regular meetings. In practice, the initiation and leadership of such a steering group require the existence of just a few champions-people who have realised how much better and more cost-effective the multidisciplinary approach can be, especially for hip fracture patients, which are the most numerous and costly patient group. Although the steering group itself needs to be kept to a manageable size in order to have efficient meetings, it is important that the wider healthcare workers involved in the whole hip fracture pathway are engaged 
on an occasional basis. This helps to raise the general level of knowledge and foster commitment among the wider MDT.

The steering group needs to decide how to operationalise the orthogeriatric service and how each phase of care should be delivered. This is determined by research, consensus of good clinical practice and clinician experience (subsequent chapters of this book describe these good practices in more detail in each phase of care). Even at this planning stage, there needs to be engagement with healthcare managers and relevant stakeholders.

When analysing and addressing gaps in care, there are two managerial strategies that have been recognised to support this process. One, the "five whys," [10] is a sequential means of addressing the superficial, symptomatic problems that are immediately obvious and then breaking them down in stages to get to the real underlying issues. Asking the question "why?" five times often reveal problems that the service user was previously unaware of. The second strategy is to perform a SWOT (strengths, weaknesses, opportunities and threats) analysis [11]. This allows the organisation to concentrate on internal factors (strengths and weaknesses of the existing service) and external factors (opportunities and threats that the new service provides). This gives a very clear global view of the situation and often reveals issues that were previously not considered. Both analyses rely on the steering group brainstorming, which circumvents the bias of a single proponent.

\subsubsection{Step 4: Evaluate the Resources Required to Drive Change Within the Organisation}

The resource required is more than just the finances needed to establish the service. Devised in 1980 by Waterman and colleagues, the "Seven S" model (Fig. 5.1) is a way of thinking holistically about the resources required to drive change within the organisation to achieve the components of optimal hip fracture care [12]. Each "S" must be addressed in order to meet management criteria:

- Staff-Are the right staff members in place to facilitate the introduction of the new orthogeriatric service? Are more or fewer staff required? Means of appropriate recruitment need to be considered.

- Skills-Do the staff have the necessary expertise? Do they require more training?

- Structure-Does the existing organisational structure lend itself to supporting this venture? The answer in most acute hospitals is "yes" as most surgical departments are already performing hip surgery. This is a natural evolvement of an existing service.

- Shared values-All parties involved in the change have to truly believe in the process in order for it to be implemented smoothly. Management, ward, theatre staff, and surgeons all need to back the venture, and this will only happen if all parties are involved in the whole process from its conception to its execution. There must be an opportunity for discussion and debate. 
Fig. 5.1 The seven $\mathrm{S}$ model developed by Peters, Philips and Waterman. (Adapted from Business Horizons [12])

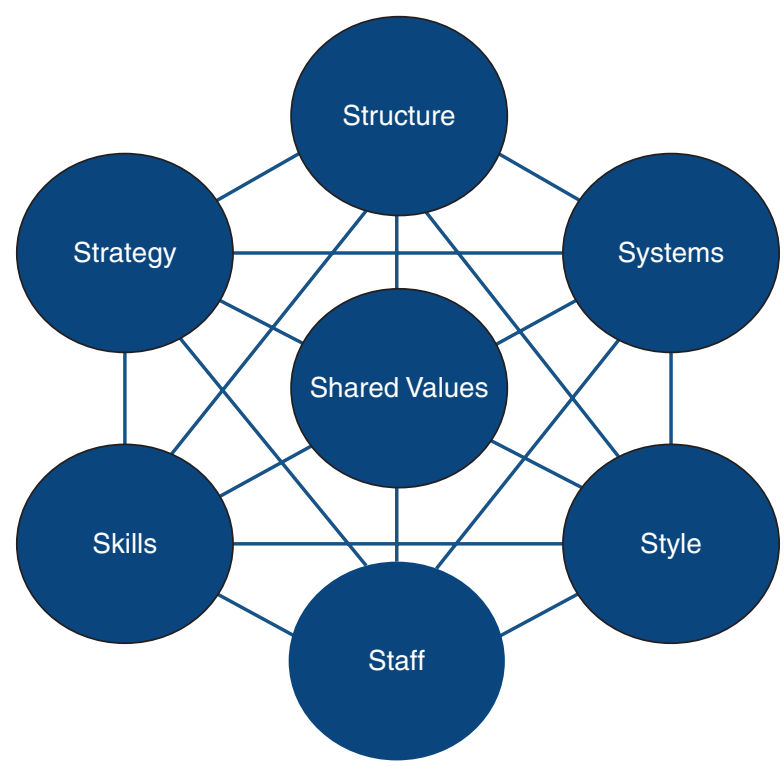

- Style of management-Is the current management style appropriate to oversee this? The orthogeriatric service needs to be driven predominantly by the core MDT with management as willing co-partners; a management autocracy here is not appropriate.

- Strategy-Are the steps in place to facilitate change? All staff providing hip fracture care need to know about the patient pathway; patients need to be informed about new services, and ward staff have to change existing care protocols to make them more specific. A global, long-term strategy is required to ensure success.

- Systems - This encompasses all aspects from information technology to patient support. Existing systems may need to be adapted.

\subsubsection{Step 5: Develop the Business Case for the Orthogeriatric Service}

The previous steps and information gathered up to this point should provide the basis for the business case for the planned orthogeriatric service. The business case is a concise document that will take the recipient, usually the relevant healthcare managers, on a journey from conception of the idea (justify why it is required) to delivery of the service (how it can be delivered). It aims to persuade those in charge of finances and service provision how an orthogeriatric service can benefit the patient, department, hospital and wider organisation. It must leave no stone unturned and be subjected to intense scrutiny. The business case also has to match with what 
is feasible and can be realistically delivered. The business case should be broken down into several subheadings and should include:

- Project title

- Summary statement

- Background

- Description of the service

- Benefits analysis

- Project planning

The United Kingdom National Hip Fracture Database website has a resource section (NHFD) [8], which includes an orthogeriatric care handbook and contains:

- Suggested job plans for ortho-geriatricians and specialist nurses in orthogeriatrics

- Links to publications describing different models of orthogeriatric care

- Model business cases and links to publications demonstrating cost-effectiveness

\subsubsection{Step 6: Implementing and Sustaining the Service}

When the business case has been approved by the hospital board, which will include executive and non-executive members, managers, clinicians and financial representatives, the service may be started as either a small pilot of the whole orthogeriatric pathway or implementation of certain phases of the pathway (Table 5.1). The service, overseen by the steering group, aims to implement the good practice that will be further described in subsequent chapters of this book.

The process does not stop with the implementation of the orthogeriatric service. It has to be followed by constant evaluation of the service and quality improvement work led by the steering group to sustain and develop it. The Plan, Do, Study, Act (PDSA) cycle, is a widely accepted and used framework for developing, testing and implementing change [13] (Fig. 5.2).

\section{Example of a PDSA Cycle Used to Improve Care}

Plan

Patients with hip fracture on anticoagulation waited longer to go to theatre compared to those not on an anticoagulant. A quality improvement project was performed to report on the scale of the problem and identify potential solutions.

Do

An analysis was conducted using hospital service level data and patient case notes retrospectively. Data collected on how much longer patients waited, its clinical impact and where these delays occurred. 
Study

Patients on vitamin K antagonists (warfarin) waited almost $24 \mathrm{~h}$ longer and those on direct oral anticoagulants (DOACs) waited over $48 \mathrm{~h}$ longer than those not on any anticoagulation. These patients had a longer length of stay. There were delays in identifying these patients, administering vitamin $\mathrm{K}$ to reverse the effects of warfarin, delays in repeating the coagulation profile post-reversal, uncertainty over when the DOAC was last taken and variation in surgeons' instructions on how long to wait for surgery after the last dose.

Act

A guideline on anticoagulation management in the peri-operative hip fracture period was written which addressed the reversal of warfarin and DOACs, monitoring of coagulation profile and when it is safe to operate. The admission documentation was altered to explicitly ask if the patient is on anticoagulation and when it was last taken. The steering group sought consensus on time to theatre. These steps standardised anticoagulation management and reduce variation in practice. An audit was embedded into the guideline to benchmark clinical practice with published standards.

It is important to remember that a successful implementation of an orthogeriatric service does not guarantee its success. It needs to be sustained and developed. This has to be paced appropriately with constant re-evaluation of the pathway to ensure resources match the provision of service. The steering group and leadership within it need to drive this. There is a wealth of literature that has reported on sustainability

Fig. 5.2 PDSA cycle. (Adapted from NHS Improvement [13])

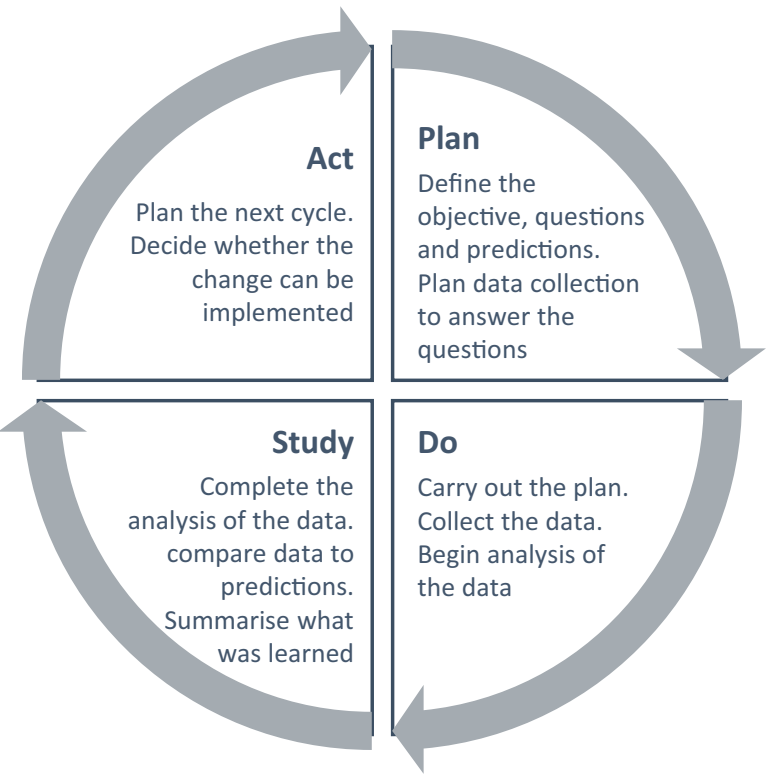


and improvement in healthcare [14-16]. In a report by the health service body, NHS Improvement, they highlighted six key factors to sustainability [14].

1. Supportive management structure

2. Structures (e.g., IT systems and infrastructure) to foolproof change so that embedding takes place

3. Improvement supported by robust, transparent feedback systems + PDSA cycles

4. Effective collaboration across many levels from managers to front line staff and a shared sense of the systems to be improved

5. Culture of improvement with engaged staff and patients

6. Formal capacity building programs through formal and informal training

\subsubsection{Step 7: Collect Evidence of Service Improvement: Audit}

The audit is a way of measuring what is being delivered against a defined quality standard. National audits such as the United Kingdom Scottish Hip Fracture Audit and the National Hip Fracture Database (NHFD) across England, Wales and Northern Ireland have allowed individual hospitals to continuously audit their care based on agreed quality standards and benchmark it against other units. These audits have been very useful in sustaining and driving improvement in hip fracture within hospitals and across the country overall. National audits exist in countries where orthogeriatric service is delivered routinely; however, in places where this is not the case, regular review of what is delivered using robust audit processes across the pathway still needs to be embedded into the service. Agreed audit standards by the steering group need to measure what is delivered (process and service outcomes) by the whole orthogeriatric service. These quality standards need to be important and realistically deliverable within the time frame allocated. This is different from clinical outcome measures, such as length of stay, mortality and medical complications.

An Example of Audit Standards: Adapted from the Scottish Standards of Care for Hip Fracture Patients [17]

1. Patients with a hip fracture are transferred from the Emergency Department to the orthopaedic ward within $4 \mathrm{~h}$.

2. Within $24 \mathrm{~h}$ of admission
(a) Screening for delirium
(b) Assessment of nutrition
(c) Falls assessment
(d) Pressure area assessment 
3. Patients undergo surgical repair of their hip fracture within $36 \mathrm{~h}$ of admission.

4. No patients repeatedly fasted in preparation for surgery. Clear oral fluids offered up to $2 \mathrm{~h}$ prior to surgery.

5. Cemented hemiarthroplasty implants are standard unless clinically indicated otherwise.

6. An older patient receives a review by a geriatrician within $72 \mathrm{~h}$ of admission.

7. Mobilisation has begun by the end of the first day after surgery.

8. Every patient has a documented occupational therapy assessment commenced within $72 \mathrm{~h}$ of admission.

9. Every patient has an assessment or a referral for their bone health within 60 days.

10. Multidisciplinary team meeting during their acute orthopaedic admission.

Figure 5.3 below illustrates the use of an audit cycle to measure and improve the assessment of delirium in patients with hip fractures [18].

Besides audit, all orthogeriatric services need to have a robust governance process, where learning from harms, morbidity and mortality reviews happen regularly. This promotes a culture of open learning to improve care. Furthermore, hip fracture

\section{Maintaining improvements}

Four-montly snapshot audit of 10 case notes to maintain improvement

\section{Making improvements}

Not all patients were screened for delirium. When it was identified, it did not always lead to further management.

Delirium screening and management is now in the admission/assessment proforma. Training delivered to medical, nursing and allied health professional staff

\section{Preparation \& planning}

All patients $\geq 60$ years admitted

with hip fracture has to be screened for delirium using the

4AT tool within 24 hours of

admission
Measuring level of performance

Case notes reviewed retrospectively of all patients admitted in the last 2 months for delirium screening and if it triggered further management according to local delirium guidelines

Fig. 5.3 Audit cycle of delirium screening and management 
management continues to develop and remains a subject of tremendous research interest. Thus, continuing professional development and training in this area is required to keep up to date with all its developments. Information sharing, networking and specialist conferences provide an opportunity to utilise new information and good practice developed elsewhere to address specific clinical problems, for example, reversal of anticoagulation and management of direct oral anticoagulants peri-operatively.

\subsubsection{Step 8: Embrace the Support of Regional, National and International Organisations}

In many countries, there is no national musculoskeletal agenda or policy. Hence, it is important to seek support elsewhere to highlight the importance of better fragility fracture care. The World Health Organisation's report on ageing and health highlighted the importance of musculoskeletal health and preventing fractures as part of its strategy towards healthy ageing [19]. Many national and international orthopaedic and geriatric medicine societies have adopted orthogeriatric co-management as a way of delivering better care for older people with hip fractures. These societies have come together to support the work of the Fragility Fracture Network (FFN) and more recently its Global Call to Action [20]. The FFN's annual Global Congress and Regional Expert Meetings are excellent opportunities to get good ideas and advice from colleagues tackling similar problems in different countries. In addition, the role of patient or public advocates can be a powerful tool in delivering the message of orthogeriatric care and needs to be encouraged. Many lay members already sit on national boards such as the UK's Falls and Fragility Fractures Audit Programme panel. Hence, a way of sustaining an orthogeriatric service is by aligning local initiatives to a much larger national and international initiative.

\subsection{Conclusion}

This chapter has described a framework through eight steps to establish an orthogeriatric service for hip fractures. Establishing such a service is challenging, involving a high level of dedication, management and clinical staff coming together, and a great deal of commitment towards improving patient care. The growth in orthogeriatric services internationally has shown that setting this up is possible with the right approach and appropriate level of support. Orthogeriatric services have consistently delivered better care and outcomes for hip fracture patients and should be part of routine hip fracture management. 


\section{Box}

Eight steps to establishing an orthogeriatric service

1. Process mapping the hip fracture pathway

2. Identify a core multidisciplinary team and form a steering group

3. Analyse and review the patient pathway

4. Evaluate the resources required to drive change within the organisation

5. Develop the business case for the orthogeriatric service

6. Implementing and sustaining the service

7. Collect evidence of service improvement-Audit

8. Embrace the support of a regional, national and international organisation

\section{References}

1. Ellis G, Whitehead MA, Robinson D, O'Neill D, Langhorne P (2011) Comprehensive geriatric assessment for older adults admitted to hospital: meta-analysis of randomised controlled trials. BMJ 343:d6553

2. Eamer G, Taheri A, Chen SS, Daviduck Q, Chambers T, Shi X, Khadaroo RG (2018) Comprehensive geriatric assessment for older people admitted to a surgical review. Cochrane Database Syst Rev 2018(1):CD012485. https://doi.org/10.1002/14651858.CD012485.pub2

3. Kammerlander C, Roth T, Friedman SM, Suhm N et al (2010) Ortho-geriatric service-a literature review comparing different models. Osteoporos Int 21(supple 4):s637-s646

4. Grigoryan KV, Javedan H, Rudolph JL (2014) Ortho-geriatric care models and outcomes in hip fracture patients: a systematic review and meta-analysis. J Orthop Trauma 28(3):e49-e55

5. Fragility Fracture Network. http://fragilityfracturenetwork.org/global-regions/. Accessed 31 Oct 2019

6. Giusti A, Barone A, Razzano M, Pizzonia M, Pioli G (2011) Optimal setting and care organization in the management of older adults with hip fracture. Eur J Phys Rehabil Med 47(2):281-296

7. Patel JN, Klein DS, Sreekumar S, Liporace FA, Yoon RS (2020) Outcomes in multidisciplinary team-based approach in geriatric hip fracture care: a systematic review. J Am Acad Orthop Surg 28:128-133. https://doi.org/10.5435/JAAOS-D-18-00425

8. National Hip Fracture Database. http://www.nhfd.co.uk/20/hipfractureR.nsf/ResourceDisplay. Accessed 31 Oct 2019

9. British Geriatrics Society. https://www.bgs.org.uk/resources/clarification-of-training-requirements-for-higher-specialist-trainees-in-geriatric-0. Accessed 31 Oct 2019

10. Pojasek RB (2000) Asking "Why" five times. Environ Qual Manag 10(1):79-84

11. Cranfield S, Ward H (2006) Managing change in the NHS: making informed decisions on change. NCCSDO, London

12. Peters TJ, Waterman RH, Phillips JR (2006) The seven S model - a managerial tool for analysing and improving organizations. NCCDSO, London

13. NHS Improvement. https://improvement.nhs.uk/documents/2142/plan-do-study-act.pdf. Accessed 31 Oct 2019

14. NHS Institute for Innovation and Improvement. https://www.england.nhs.uk/improvementhub/wp-content/uploads/sites/44/2017/11/ILG-1.7-Sustainability-and-its-Relationship-withSpread-and-Adoption.pdf. Accessed 31 Oct 2019 
15. NHS Scotland Quality Improvement Hub. http://www.qihub.scot.nhs.uk/media/596811/ the $\% 20$ spread $\% 20$ and $\% 20$ sustainability $\% 20$ ofquality $\% 20$ improvement $\% 20$ in $\% 20$ healthcare\%20pdf\%20.pdf. Accessed 31 Oct 2019

16. Lennox L, Maher L, Reed J (2018) Navigating the sustainability landscape: a systematic review of sustainability approaches in healthcare. Implement Sci 13(1):27

17. Scottish Standards of Care for Hip Fracture Patients. https://www.shfa.scot.nhs.uk/_docs/2019/ Scottish-standards-of-care-for-hip-fracture-patients-2019.pdf. Accessed 31 Oct 2019

18. Healthcare Quality Improvement Partnership. https://www.hqip.org.uk/wp-content/ uploads/2018/02/developing-clinical-audit-patient-panels.pdf. Accessed 31 Oct 2019

19. World Health Organization. World report on ageing and health. https://www.who.int/ageing/ events/world-report-2015-launch/en/. Accessed 31 Oct 2019

20. Dreinhofer KE, Mitchell PJ, Begue T, Cooper C et al (2018) A global call to action to improve the care of people with fragility fractures. Injury 49(8):1393-1397

Open Access This book is licensed under the terms of the Creative Commons AttributionNonCommercial-NoDerivatives 4.0 International License (http://creativecommons.org/licenses/ by-nc-nd/4.0/), which permits any noncommercial use, sharing, distribution and reproduction in any medium or format, as long as you give appropriate credit to the original author(s) and the source, provide a link to the Creative Commons license and indicate if you modified the licensed material. You do not have permission under this license to share adapted material derived from this book or parts of it.

The images or other third party material in this book are included in the book's Creative Commons license, unless indicated otherwise in a credit line to the material. If material is not included in the book's Creative Commons license and your intended use is not permitted by statutory regulation or exceeds the permitted use, you will need to obtain permission directly from the copyright holder.

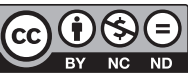

